\title{
The Global Influence of the Madden-Julian Oscillation on Extreme Temperature Events*
}

\author{
SATOKo MATSUEDA AND YUHEI TAKAYA \\ Climate Prediction Division, Japan Meteorological Agency, Tokyo, and Climate Research Department, \\ Meteorological Research Institute, Japan Meteorological Agency, Tsukuba, Japan
}

(Manuscript received 7 September 2014, in final form 6 March 2015)

\begin{abstract}
The authors investigated the influence of the Madden-Julian oscillation (MJO) on extreme warm and cold events, which may have large social and economic impacts. The frequencies of extreme temperature events were analyzed and compared between active and inactive MJO periods by using the 7-day running average of the $850-\mathrm{hPa}$ temperature during the extended boreal winter (November-April). The results show that the frequency of extreme events is significantly modulated (i.e., increased by a factor of more than 2) by the MJO with a time lag over some areas in the extratropics as well as in the tropics. In the extratropics, the modulation of the frequency of the extreme events is roughly associated with midlatitude wave responses to tropical forcing and anomalous lower-level circulation due to the MJO.

The relationship between the MJO and forecast skill of extreme temperature events was also investigated by using a suite of hindcasts made with the operational one-month ensemble prediction system of the Japan Meteorological Agency. Forecast skill of extreme events occurring after active MJO periods tend to be better over some areas, compared with after inactive MJO periods. These results suggest that a realistic representation of the $\mathrm{MJO}$ and of the atmospheric response to the $\mathrm{MJO}$ in forecast models is important for providing reliable early warning information about extreme events.
\end{abstract}

\section{Introduction}

The Madden-Julian oscillation (MJO) is the dominant mode of intraseasonal variability in the tropics (Madden and Julian 1994; Zhang 2005), and it influences weather and climate over not only the tropics but also the extratropics (e.g., Matthews et al. 2004). Previous studies have examined various regional influences of the $\mathrm{MJO}$ on, for instance, precipitation over East Asia (Jeong et al. 2008), the intraseasonal fluctuations of the Australian summer monsoon (Hendon and Liebmann 1990), precipitation in Australia (Wheeler et al. 2009), winter surface temperature in Canada and North America (Lin and Brunet 2009; Schreck et al. 2013; Zhou et al. 2012), winter precipitation in Canada (Lin et al. 2010), the South American summer

\footnotetext{
* Supplemental information related to this paper is available at the Journals Online website: http://dx.doi.org/10.1175/JCLI-D-14-00625.s1.

Corresponding author address: Satoko Matsueda, Climate Prediction Division, Japan Meteorological Agency, 1-3-4 Otemachi, Chiyoda-ku, Tokyo 100-8122, Japan.

E-mail: matsueda@met.kishou.go.jp
}

rainfall and circulation (Paegle et al. 2000; Carvalho et al. 2004), and precipitation in Africa (Pohl and Camberlin 2006; Alaka and Maloney 2012).

Modulation by the MJO of extratropical atmospheric circulation patterns, such as the North Atlantic Oscillation (NAO; Cassou 2008; Lin et al. 2009) and the PacificNorth American (PNA) pattern (Mori and Watanabe 2008), has also been investigated. The representation of these teleconnections was examined in the ECMWF forecast system (Vitart and Molteni 2010).

Moreover, the MJO may induce the occurrence of extreme weather events, which can have large societal and economic impacts. Jones et al. (2011) demonstrated a relationship between the MJO and extreme precipitation over the United States and Hong and Li (2009) investigated the extreme cold anomaly over Southeast Asia in February 2008. The main purpose of this paper is to discuss the global influence of the MJO on the extreme warm and cold conditions.

The MJO has been thought to have a potential predictability up to one month(Waliser et al. 2003; Reichler and Roads 2005; Ding et al. 2010) and to be a source of forecast predictability in the extratropics (Jones et al. 
2004; Ferranti et al. 1990). Therefore, reliable forecasts of extreme weather events derived from the MJO signals would potentially be useful for disaster mitigation and risk management in various societal and economic sectors. In this study, we investigated the lagged influence of the MJO on the frequency of extreme warm events (EWEs) and extreme cold events (ECEs) for different time lags during the extended boreal winter (November-April). For brevity, we focused on cases with a 3-9-day lag after particular phases of the MJO. Interpretations of the modulation of extreme event frequency by the MJO were discussed in relation to anomalous atmospheric circulation patterns associated with the MJO. In addition, we explored the impact of the MJO on the forecast skill of extreme events.

The rest of the paper is organized as follows. The data and methods are described in section 2. In section 3, modulations of EWE and ECE frequency associated with the MJO are described, and these modulations are interpreted by referring to anomalous atmospheric circulation fields. In section 4, forecast skill of extreme events after active MJO periods are compared with those after inactive MJO periods. Section 5 discusses the dependency of our results on MJO indices and target elements, and links between the extreme events and circulations in response to the MJO. A summary is provided in section 6 .

\section{Data and methods}

The Japanese 55-year Reanalysis (JRA-55) dataset (Ebita et al. 2011; Kobayashi et al. 2015) and the National Oceanic and Atmospheric Administration (NOAA) outgoing longwave radiation (OLR) data (Liebmann and Smith 1996) were used on a $2.5^{\circ}$ grid for the period from 1981 to 2010.

To examine forecast skill of extreme events, we used a set of hindcasts made with the one-month ensemble prediction system of the Japan Meteorological Agency (JMA) (Hirai et al. 2014; Sato et al. 2014) operated from March 2014. The five-member-ensemble hindcasts were carried out with an atmospheric general circulation model with a spectral resolution of triangular truncation at wavenumber 319 using a linear Gaussian grid and 60 vertical levels (TL319L60). The initial forecast dates were the 10th and 20th and the end of each month for the hindcast period (1981-2010). Initial conditions of the atmospheric fields were obtained from the JRA-55 dataset. Oceanic boundary conditions were obtained from the Merged Satellite and In situ Data Global Daily Sea Surface Temperature (MGDSST; JMA 2013) analysis. The SST was prescribed with a persisted anomaly.

The MJO index (Wheeler and Hendon 2004) was computed as described by Gottschalck et al. (2010). A combined empirical orthogonal function (CEOF) analysis was applied to the daily OLR and zonal wind (850- and 200-hPa zonal winds) fields, averaged over the tropics $\left(15^{\circ} \mathrm{S}-15^{\circ} \mathrm{N}\right)$ for the period from 1981 to 2010 . Before the CEOF analysis, the long-term ( $30 \mathrm{yr})$ mean and the climatological seasonal cycle (first three harmonics) were removed. In addition, the most recent 120-day mean was subtracted to remove interannual variability such as that associated with the El Niño-Southern Oscillation (ENSO). Finally, each field was normalized by the square root of its zonally averaged variance. The MJO index was defined as the normalized principal components (PCs) of the first and second CEOFs (PC1 and PC2). MJO phases $1-8$ were defined as eight sections in the phase space spanned by $\mathrm{PC} 1$ and PC2. The MJO amplitude was defined as $\left(\mathrm{PC}^{2}+\right.$ $\left.\mathrm{PC}^{2}\right)^{1 / 2}$. In each phase, an active MJO event was defined as a period of time when the $\mathrm{MJO}$ amplitude was greater than 1. Figure 1 shows composite maps of OLR and 200-hPa wind anomalies for each active MJO event. An area of enhanced convection can be seen to propagate eastward from Africa and the western Indian Ocean via the Maritime Continent to the Pacific. It is noted that the spatial structures of the CEOFs are shifted to the east about $30^{\circ}$ longitude compared with those described in Wheeler and Hendon (2004), related to uncertainty of 850-hPa zonal wind analysis (cf. Bechtold et al. 2013). Specifically, the differences in the spatial structures of CEOFs are mainly attributed to differences of $850-\mathrm{hPa}$ zonal wind seen among reanalyses: JRA-55, ERAInterim (Dee et al. 2011), and NCEP-NCAR Reanalysis 1 (Kalnay et al. 1996) (T. Komori and Y. Kubo, JMA, 2015, personal communication).

In this study, we focused on extreme events defined as follows. First, we obtained the 95th and 5th climatological percentiles of the 7-day running average (moving average) of the 850-hPa temperature (T850), calculated for each calendar date over the 30 years from 1981 to 2010. Then, we applied 15-day running average of those percentiles to obtain smoothly varying thresholds. Last, we defined an EWE to occur when the 7-day running average of T850 exceeded the 95th percentile threshold, and an ECE to occur when it fell below the 5 th percentile threshold.

Figure 2 shows the 95th and 5th percentiles of the T850 anomaly averaged over the extended boreal winter (November-April). The larger amplitudes of the percentile values over land areas in the extratropics such as in North America suggest that these extreme events could have large societal impacts.

The extreme event thresholds for hindcasts were defined as the 95th (5th) climatological percentiles, estimated from 450 hindcast integrations; each integration was carried out by the 5-member ensemble and was started on three initial dates-the initial date and the 

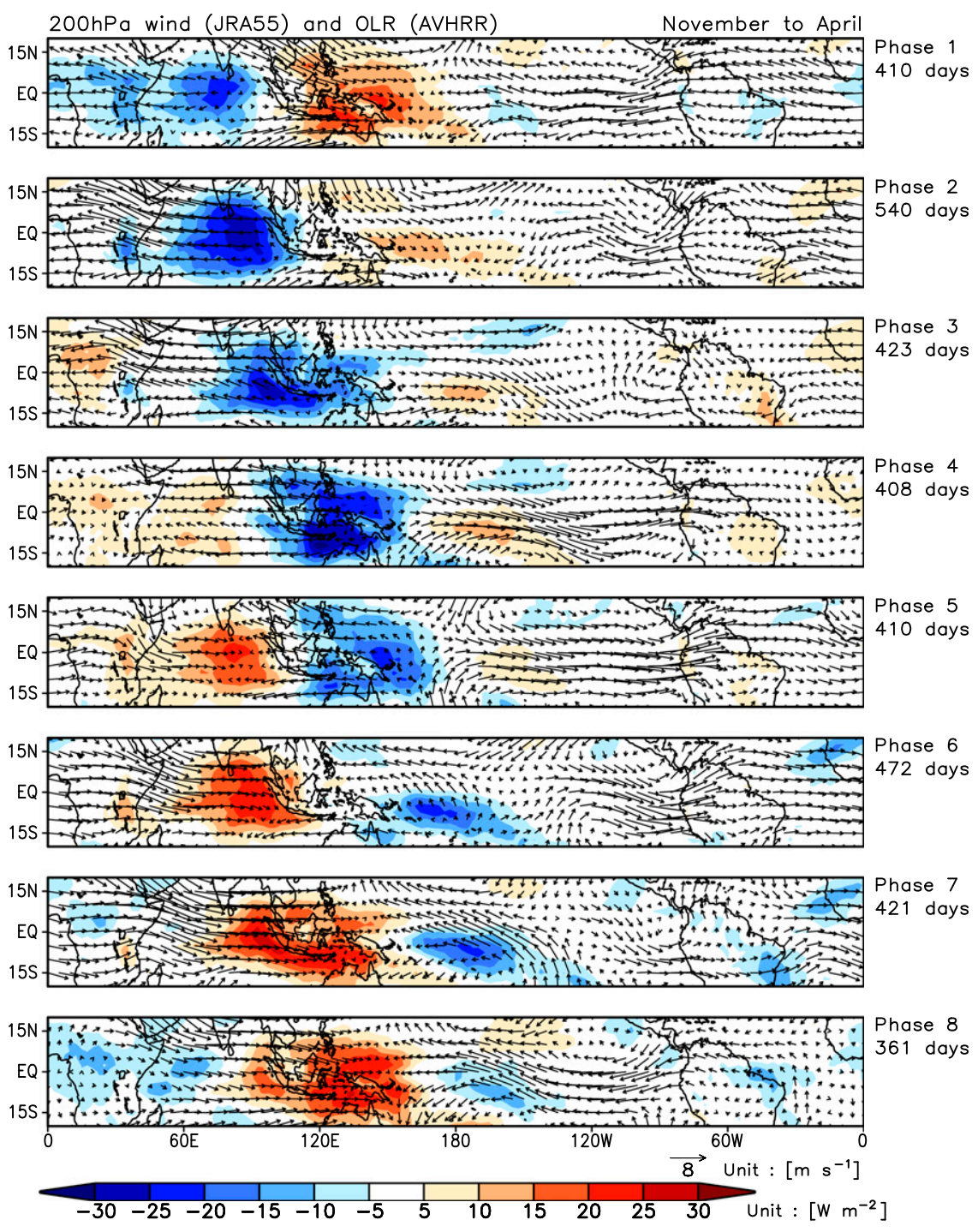

FIG. 1. Composites of OLR ( $\mathrm{W} \mathrm{m}^{-2}$, shaded) and the $200-\mathrm{hPa}$ wind ( $\mathrm{m} \mathrm{s}^{-1}$, vectors) anomaly during each active MJO phase from November to April. The number of days in each active MJO phase is shown to the right of each figure.

previous and following dates-for each year during the period from 1981 to 2010. For example, the thresholds for hindcasts initialized on 10 January were estimated from all of hindcast integrations started on 31 December, 10 January, and 20 January in the period from 1981 to 2010.

We applied a resampling (bootstrap) method to determine the statistical significance of differences in extreme event frequency between active and inactive MJO conditions (see the appendix for details). Forecast skill of extreme events were measured by the hit rate, which we defined as the ratio of the number of successful extreme event forecasts to the number of observed extreme events. The hit rate was calculated from the individual ensemble forecasts.

\section{Modulation of extreme event frequency and large-scale atmospheric circulations during active MJO events}

The MJO has a lagged influence on weather and climate in the extratropics (e.g., Lin and Brunet 2009; Schreck et al. 2013; Lin et al. 2010; Cassou 2008; Lin et al. 2009; Mori and Watanabe 2008). Therefore, we investigated MJO modulations of extreme event frequency for different time lags. For brevity, we focus on cases of extreme events with a 3-9-day lag after particular phases of the MJO. We calculated the ratio of EWE (ECE) frequency occurring with a period of 3-9 days after active MJOs to the frequency after inactive MJOs 

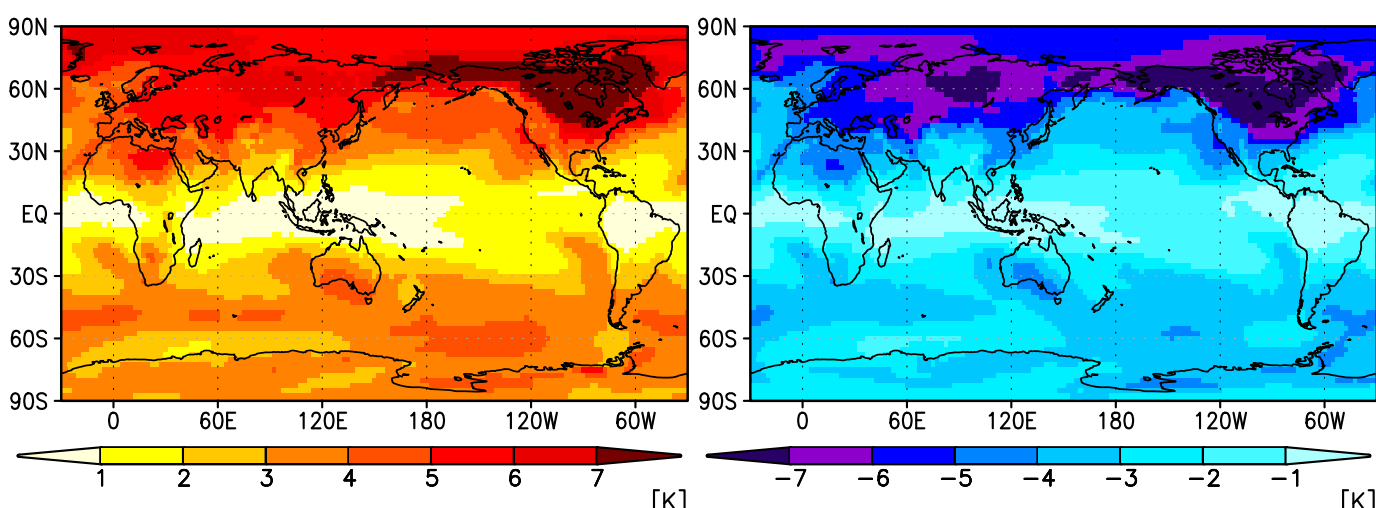

FIG. 2. T850 anomaly thresholds (K) for extreme (left) warm and (right) cold events averaged from November to April.

(Fig. 3). The result shows that, in the tropics, including central Africa, Central America, and northern South America, modulations of extreme event frequency are likely caused by the direct impact of convection anomalies associated with the MJO (Fig. 3). It is noteworthy that we obtained essentially the same results even if the frequency ratios in each year were averaged over 30 years to mitigate the effects of interannual variations such as those due to ENSO (not shown).

To better interpret the dynamical links between the MJO and its modulations of extreme event frequency, we calculated lagged composites for the 7-day running average $850-\mathrm{hPa}$ streamfunction anomaly (PSI850; Fig. 4) and for the 500-hPa geopotential anomaly (Z500; Fig. 5) during the extended boreal winter. Next we present an overview of the characteristic features in different regions in the extratropics.

\section{a. Asia}

EWE (ECE) frequency is increased by a factor of more than 2 or 3 over central Asia with the MJO over the western hemisphere and South Africa (in the Indian Ocean) in phase 7 (phases 1-2). These modulations correspond to anticyclonic (cyclonic) extratropical circulation anomalies during the active MJO, as seen in the Z500 lag composites (Fig. 5). These anomalies are likely related to the Eurasian (EU) teleconnection pattern. Around Japan, the EWE (ECE) frequency is increased by a factor of more than 2 with the eastward propagation of enhanced (suppressed) convection in the Indian Ocean in phases 8-1 (phases 4-5). These modulations are caused by weak (strong) troughs corresponding to a positive (negative) Z500 (Fig. 5). North of the Bay of Bengal, EWE frequency is increased by a factor of more than 2 or 3 with the eastward propagation of suppressed phases in the Indian Ocean in phases 4-6. These modulations correspond to anticyclonic circulation anomalies in the Z500 lag composites (Fig. 5).

\section{b. Australia and Oceania}

EWE frequency is increased by a factor of more than 2 over southern Australia with the eastward propagation of enhanced convection in the Indian Ocean in phases 1-2. EWE frequency is increased by a factor of more than 2 from around Melanesia to northern New Zealand with the eastward propagation of enhanced convections toward the Maritime Continent in phases 3-5. In Australia and Oceania, the modulations are consistent with lowerlevel circulation anomalies in association with the active MJO, seen in the PSI850 lag composites (Fig. 4). Warm air advection from the low latitudes, west of a cyclonic circulation anomaly or east of an anticyclonic circulation anomaly (over southern Australia in phases 1-2 or from around Melanesia to northern New Zealand in phases 3-5), result in the increased EWE frequency.

\section{c. North America}

In northeastern North America, EWE frequency is increased by a factor of more than 2 or 3 with the eastward propagation of enhanced convection from the western Indian Ocean to the Maritime Continent in phases 2-5. EWE frequency is increased by a factor of more than 2 from northern Alaska to northwestern Canada, or over northeastern Canada, with the eastward propagation of enhanced convection from the western to the central equatorial Pacific in phases 6-7. In central North America, ECE frequency is increased by a factor of more than 2 with the eastward propagation of enhanced convection in the central equatorial Pacific in phase 7. Teleconnection patterns such as a PNA-like pattern and the NAO pattern can be seen over the central Pacific-North America in association with the MJO (Fig. 5). These teleconnection patterns are consistent with previously reported patterns (e.g., Cassou 2008; Lin et al. 2009; Mori and Watanabe 2008), and they lead to increased frequencies of EWEs or ECEs 

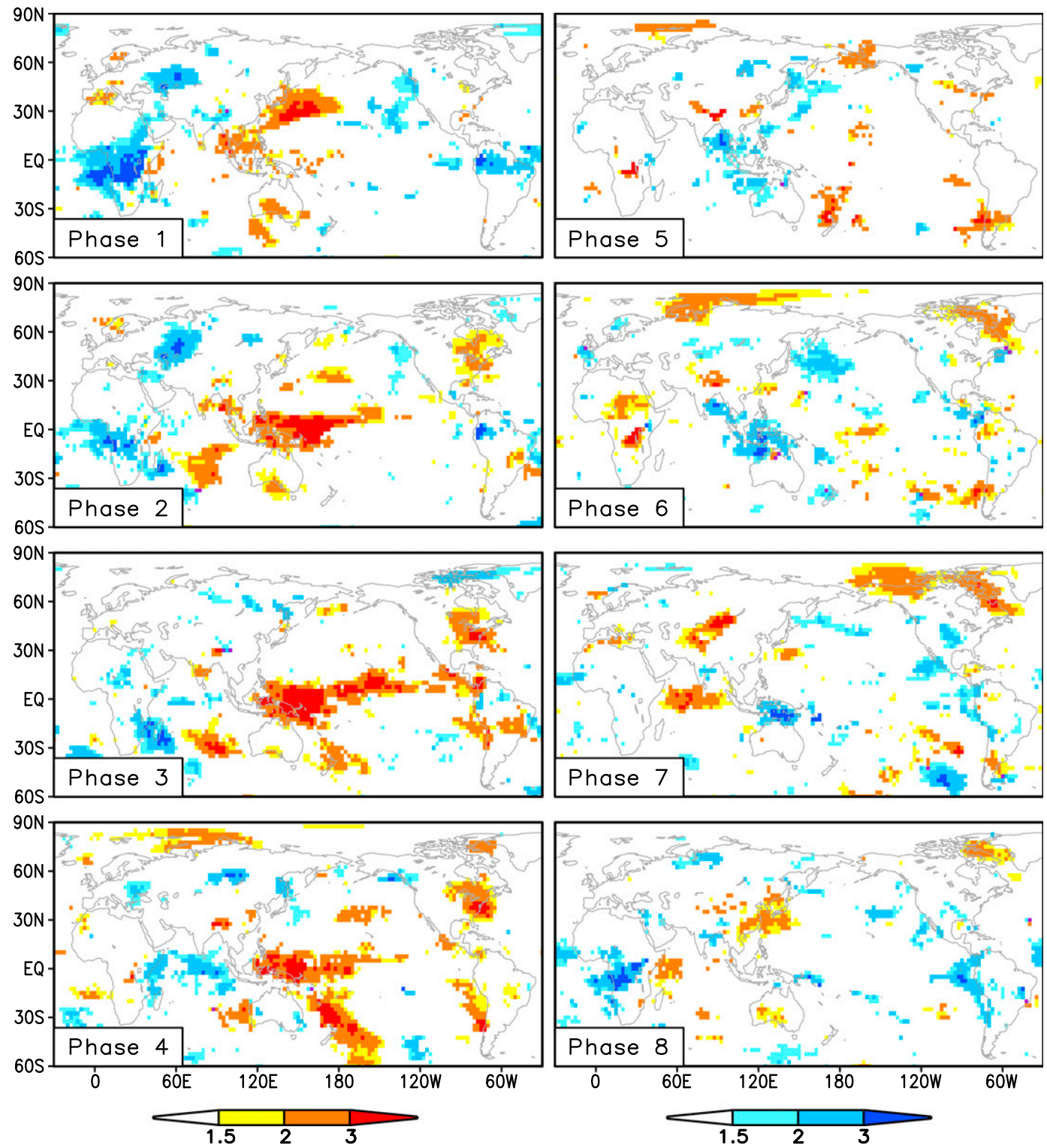

FIG. 3. Ratios of the occurrence frequency, from November to April, of T850 extreme warm (warm colors) and cold (cold colors) events following active MJOs to those following inactive MJOs with a 3-9-day lag. The ratios are plotted only in areas where the frequency increases following active MJOs were significant at the $95 \%$ confidence level. Areas colored purple are points where the frequency of both warm and cold events increased at the $95 \%$ confidence level.

over North America. These results agree with previous reports of an influence of the MJO on surface temperature anomalies in Canada (Lin and Brunet 2009) and North America (Schreck et al. 2013; Zhou et al. 2012).

\section{d. South America}

EWE frequency is increased by a factor of more than 2 over southern Brazil with the eastward propagation of enhanced convections over the eastern Indian Ocean in phases $2-3$. This modulation corresponds to lower-level anticyclonic circulation anomalies during the active $\mathrm{MJO}$, as seen in the PSI850 lag composites (Fig. 4). In southern Chile and Argentina, EWE frequency is increased by a factor of more than 2 or 3 with the eastward propagation of enhanced convections from the Maritime Continent to the central equatorial Pacific in phases 4-7. This modulation corresponds to a positive Z500 (Fig. 5).

\section{e. Europe}

In some parts of Scandinavia, EWE frequency is increased by a factor of more than 2 with the eastward 

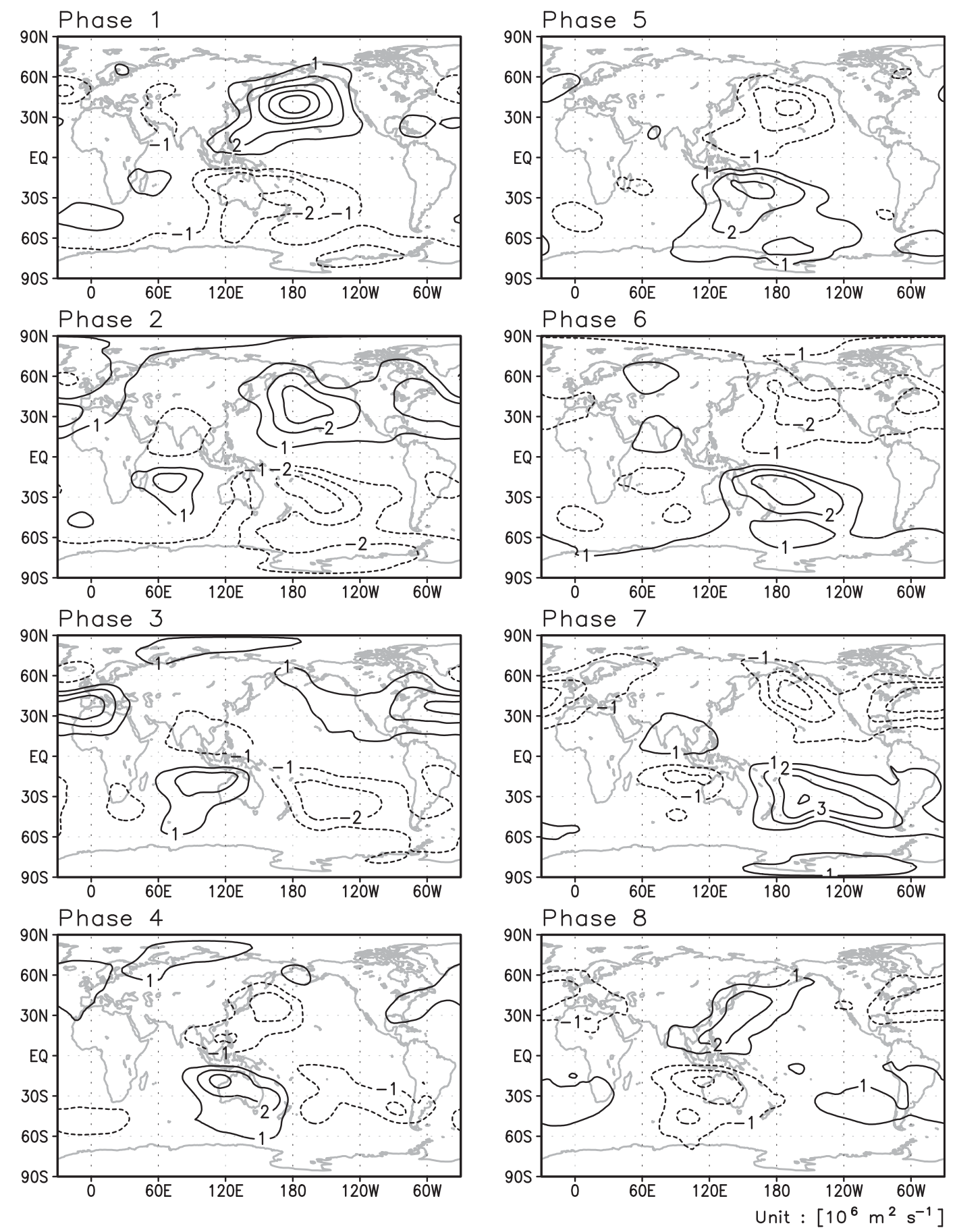

FIG. 4. Composites of the 850 -hPa streamfunction anomaly $\left(10^{6} \mathrm{~m}^{2} \mathrm{~s}^{-1}\right)$ with a 3-9-day lag from each active MJO phase, from November to April. Solid line contours represent the positive anomaly and dashed line contours represent the negative anomaly.

propagation of enhanced convections over Africa and the Indian Ocean in phase 1-2. This modulation corresponds to a positive Z500 (Fig. 5), which is likely related to the EU pattern as seen in Asia. Around eastern
Europe, ECE frequency is increased by a factor of more than 2 with enhanced convection over the Maritime Continent in phase 4. However, this modulation does not seem to be related to any discernible 


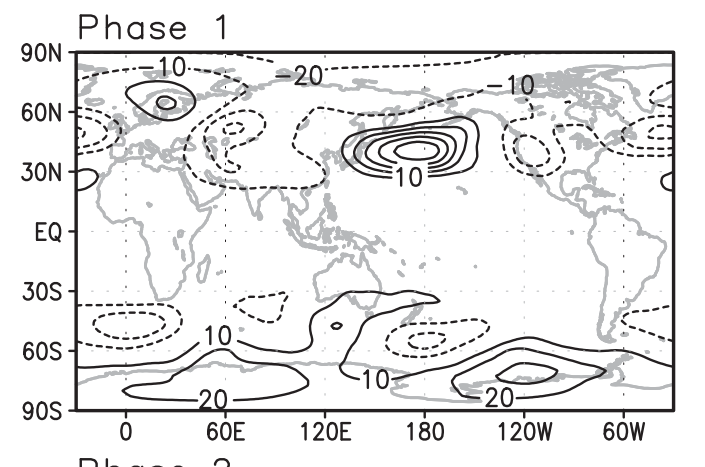

Phase 5
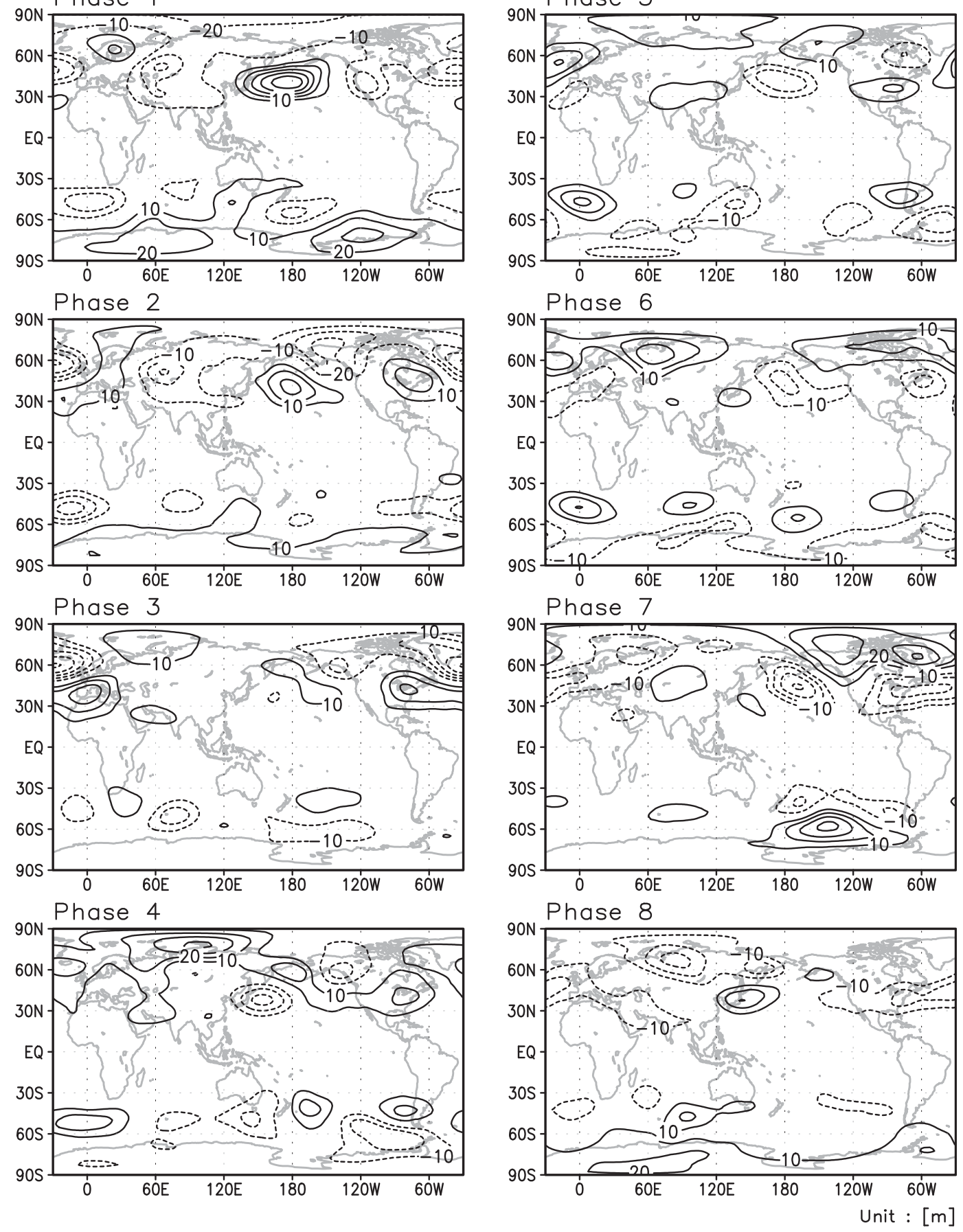

FIG. 5. Composites of the 500-hPa geopotential height anomaly (m) with a 3-9-day lag from each active MJO phase, from November to April. Solid line contours represent the positive anomaly and dashed line contours represent the negative anomaly.

anomalous circulation associated with the MJO. In Europe, the MJO modulates EWE and ECE frequency over a smaller region compared with other parts of the world.

\section{f. Africa}

ECE frequency is increased by a factor of more than 2 around Madagascar with the eastward propagation of 

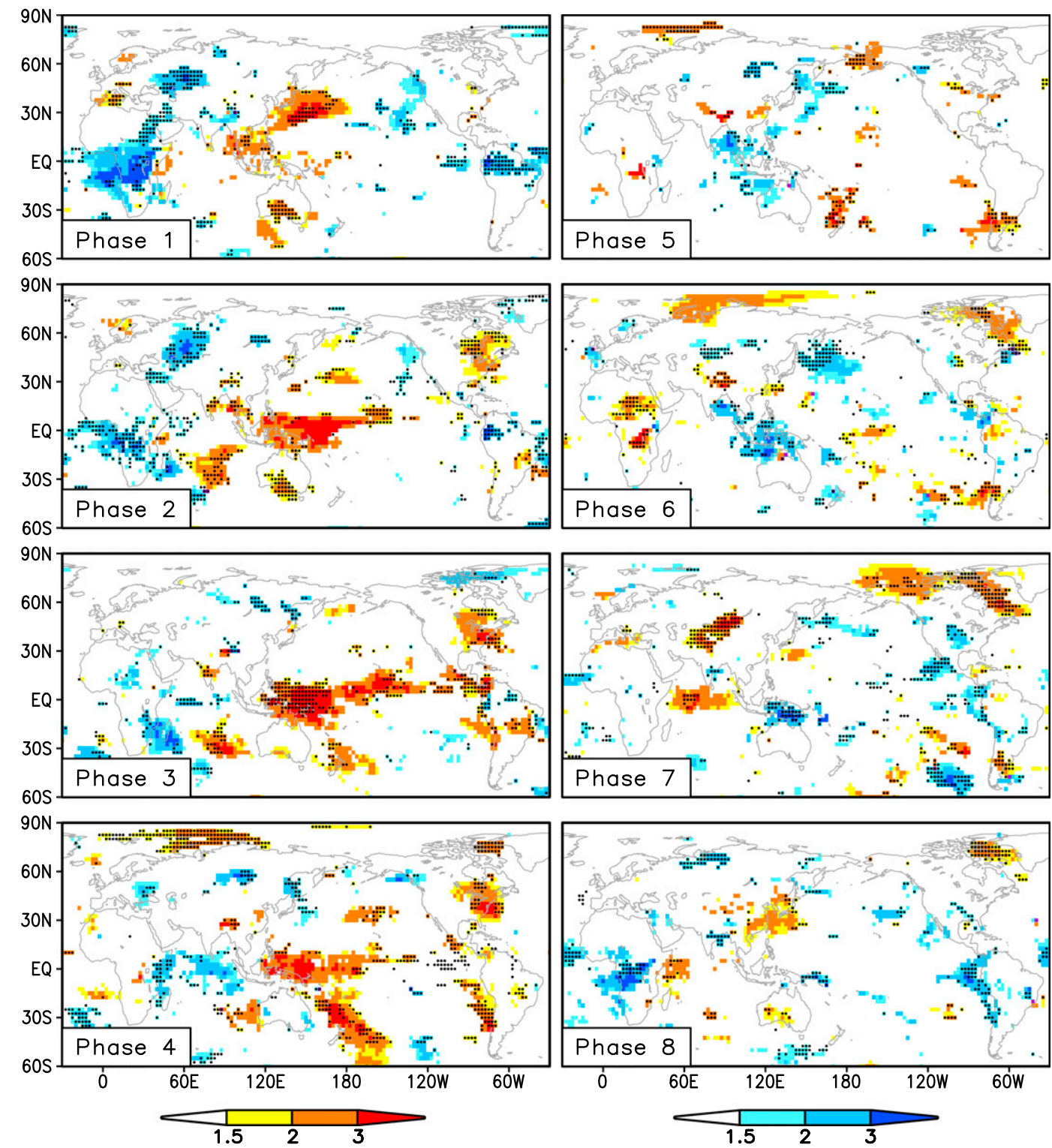

FIG. 6. As in Fig. 3, but black dots indicate where the forecast skill (hit rate) of T850 extreme warm or cold events with a lead time of 8 days during the active MJOs was better than it was during inactive MJOs (no significance test).

enhanced convection in the Indian Ocean to the Maritime Continent in phases $2-3$. This modulation is likely caused by cold air advection from the low latitudes associated with lower-level circulation anomalies seen in the PSI850 lag composites (Fig. 4).

\section{Forecast skill of extreme events during active MJOs}

EWEs and ECEs that are associated with active MJOs are expected to be more predictable by dynamical forecast models than those not associated with active MJOs. The MJO forecast in the model is skillful up to about two weeks, although the model underestimates the MJO amplitude (Sato et al. 2014). In addition, the model reasonably represents atmospheric responses to the MJOs to a large extent (see Figs. S1 and S2 in the supplemental material). To investigate the influence of the MJO on forecast skill of extreme events, we calculated the hit rate for extreme events separately after active and inactive MJOs. Then we compared the forecast skill in predicting EWEs and ECEs between those that lagged active MJOs and those that lagged inactive MJO with a lead time of 8 days (Fig. 6). As before (see Fig. 3), we focus on cases with a 3-9-day lag after particular phases of the MJO. We obtained the similar 
results at lead times of up to two weeks (not shown). Statistical significance is not shown because the sampling size was insufficient; thus, the results are useful only for reference. In the areas where extreme event frequency is increased in association with the MJO, events that occurred after active MJOs are better predicted than those that occurred after inactive MJOs. The improvement is obtained especially over Asia and Australia, presumably because of more robust influences by strong convective anomalies in Indian Ocean and Maritime Continents. This result suggests that forecast skill of extreme events may improve after active MJOs compared with after inactive MJOs. The improvement is, however, limited around Japan and over North America, presumably because of underestimates of the MJO amplitude in the model (Sato et al. 2014) or unreasonable representation of the responses to the MJO forcing in the model. If so, then improvement of skill for predicting MJO and MJO responses would result in better predictions of EWEs and ECWs.

\section{Discussion}

Here we first discuss the dependency of our results on definitions of active MJO periods. The modulations of the frequency of extreme events by the MJOs are also seen when we use other definitions of the MJOs such as OLR-based indices proposed by Kiladis et al. (2014) (not shown). However, the intensity of the modulations using our MJO definitions differs from that using OLRbased MJO definitions to some extent. This is presumably because the MJOs defined by circulation and OLR fields have stronger circulation impacts than the MJOs defined by OLR-only fields as discussed by Kiladis et al. (2014).

We also note that the similar results are obtained for surface temperature instead of T850 except for the tropics. In the tropics, the modulations for the extreme surface temperature are weak and show opposite signal to that for T850 in some of the areas (not shown). This is presumably because T850 is linked to tropospheric heating by active convections with the MJO; on the other hand, surface temperature is linked to SST. Furthermore, extreme events are locally more frequent after the strong MJOs, although the sampling size is insufficient (not shown).

Anomalous circulation patterns associated with the MJO, which relate to the modulations of the frequency of extreme events, are likely forced by tropical heating. These atmospheric dynamical responses to the tropical heating were intensively studied with models with a wide range of complexity (e.g., Sardeshmukh and Hoskins 1988; Grimm and Silva Dias 1995; Jin and
Hoskins 1995; Matthews et al. 2004; Seo and Son 2012). It was shown that the MJO convective heating induces the Rossby wave train in the extratropics, such as PNA, which is generally consistent with the observed anomalies analyzed in this study. These studies support that the MJO influences the extreme temperature events in the extratropics by dynamically modulating extratropical circulations.

It is noteworthy that the influence of the MJO is not always linear or symmetric. Lin and Brunet (2009), who studied the impacts of the MJO on surface temperature in Canada, also reported nonlinearity. Furthermore, circulation anomalies associated with the MJO do not always lead to significant increases in extreme event frequencies. For instance, strong cyclonic anomalies occur from Alaska to northwestern Canada in phases 24 (Fig. 5), but corresponding increases of ECE frequency are not clear.

\section{Summary}

In this study, we examined the influences of the MJO on the frequency of extreme warm and cold events. We found that the frequency of extreme events is significantly modulated (i.e., increased by a factor of more than 2) by an active MJO, with a time lag, over some areas in the extratropics as well as in the tropics. In the extratropics, the modulations of extreme event frequency correspond roughly to midlatitude wave responses to tropical forcing or anomalous lower-level circulations due to MJOs.

Forecast skill of extreme events after an active MJO, compared to those after an inactive $\mathrm{MJO}$, are better over some areas. This result suggests that the MJO contributes to the predictability of extreme events. However, because this result was obtained from a relatively small sample, further investigations are needed, including individual case studies.

The results presented in this paper suggest that the realistic representation of the MJO and atmospheric responses to the MJO in forecast models is important for improving early warning information about extreme events.

Acknowledgments. The OLR data were provided by NOAA. We used a diagnostic package made available by the U.S. Climate Variability and Predictability Program (CLIVAR) MJO Working Group. This research was supported by the Climate Research Fund (C2) of the Meteorological Research Institute, Japan. We would thank Prof. Pedro L. Silva Dias and anonymous reviewers for their constructive comments to improve the manuscript. 


\section{APPENDIX}

\section{Significance Testing}

In this paper, we estimated the level of statistical significance by means of the so-called bootstrap method (Efron and Tibshirani 1994). First, the occurrence frequencies of extreme events during active and inactive MJOs were calculated for each year, producing 30 frequency pairs. These pairs were assumed to be independent. Then, the 30 pairs were randomly resampled, and average frequencies of the samples were calculated for active and inactive MJOs. This procedure was repeated 1000 times. When the averaged extreme event frequency during an active MJO was higher than that during an inactive MJO for more than 950 samples ( $95 \%$ of 1000 repetitions), we considered the frequency of extreme events to be significantly higher during an active MJO compared with during an inactive MJO. This method was applied in each MJO phase.

\section{REFERENCES}

Alaka, G. J., Jr., and E. D. Maloney, 2012: The influence of the MJO on upstream precursors to African easterly waves. J. Climate, 25, 3219-3236, doi:10.1175/JCLI-D-11-00232.1.

Bechtold, P., P. Bauer, J.-R. Bidlot, C. Cardinali, L. Magnusson, F. Prates, and M. Rodwell, 2013: Uncertainty in tropical winds. ECMWF Newsletter, No. 134, ECMWF, Reading, United Kingdom, 33-37.

Carvalho, L. M. V., C. Jones, and B. Liebmann, 2004: The South Atlantic convergence zone: Intensity, form, persistence, and relationships with intraseasonal to interannual activity and extreme rainfall. J. Climate, 17, 88-108, doi:10.1175/ 1520-0442(2004)017<0088:TSACZI > 2.0.CO;2.

Cassou, C., 2008: Intraseasonal interaction between the MaddenJulian Oscillation and the North Atlantic Oscillation. Nature, 455, 523-527, doi:10.1038/nature07286.

Dee, D. P., and Coauthors, 2011: The ERA-Interim reanalysis: Configuration and performance of the data assimilation system. Quart. J. Roy. Meteor. Soc., 137, 553-597, doi:10.1002/ qj. 828 .

Ding, R., J. Li, and K.-H. Seo, 2010: Predictability of the MaddenJulian oscillation estimated using observational data. Mon. Wea. Rev., 138, 1004-1013, doi:10.1175/2009MWR3082.1.

Ebita, A., and Coauthors, 2011: The Japanese 55-year Reanalysis "JRA-55": An interim report. SOLA, 7, 149-152, doi:10.2151/ sola.2011-038.

Efron, B., and R. J. Tibshirani, 1994: An Introduction to the Bootstrap. Chapman and Hall/CRC Press, $456 \mathrm{pp}$.

Ferranti, L., T. N. Palmer, F. Molteni, and E. Klinker, 1990: Tropical-extratropical interaction associated with the 3060 day oscillation and its impact on medium and extended range prediction. J. Atmos. Sci., 47, 2177-2199, doi:10.1175/ 1520-0469(1990)047<2177:TEIAWT>2.0.CO;2.

Gottschalck, J., and Coauthors, 2010: A framework for assessing operational Madden-Julian oscillation forecasts: A CLIVAR MJO working group project. Bull. Amer. Meteor. Soc., 91, 1247-1258, doi:10.1175/2010BAMS2816.1.

Grimm, A. M., and P. L. Silva Dias, 1995: Analysis of tropicalextratropical interactions with influence functions of a barotropic model. J. Atmos. Sci., 52, 3538-3555, doi:10.1175/ 1520-0469(1995)052<3538:AOTIWI >2.0.CO;2.

Hendon, H. H., and B. Liebmann, 1990: The intraseasonal (3050 day) oscillation of the Australian summer monsoon. J. Atmos. Sci., 47, 2909-2924, doi:10.1175/1520-0469(1990)047<2909: TIDOOT>2.0.CO;2.

Hirai, M., K. Miyaoka, H. Sato, H. Sugimoto, A. Minami, and C. Matsukawa, 2014: March 2014 upgrade of JMA's onemonth ensemble prediction system. CAS/JSC WGNE Research Activities in Atmospheric and Oceanic Modelling, Vol. 44, No. 6, 9-10. [Available online at http://www.wcrpclimate.org/WGNE/BlueBook/2014/individual-articles/06_Hirai_ Masayuki_WGNE_bluebook2013_K1v1403.pdf.]

Hong, C. C., and T. Li, 2009: The extreme cold anomaly over Southeast Asia in February 2008: Roles of ISO and ENSO. J. Climate, 22, 3786-3801, doi:10.1175/2009JCLI2864.1.

JMA, 2013: Outline of the operational numerical weather prediction at the Japan Meteorological Agency. Appendix to WMO Technical Progress Report on the Global Dataprocessing and Forecasting System (GDPFS) and Numerical Weather Prediction (NWP) Research, Japan Meteorological Agency, Tokyo, Japan, 138 pp. [Available online at http:// www.jma.go.jp/jma/jma-eng/jma-center/nwp/outline2013-nwp/ index.htm.]

Jeong, J.-H., B.-M. Kim, C.-H. Ho, and Y.-H. Noh, 2008: Systematic variation in wintertime precipitation in East Asia by MJOinduced extratropical vertical motion. J. Climate, 21, 788-801, doi:10.1175/2007JCLI1801.1.

Jin, F., and B. J. Hoskins, 1995: The direct response to tropical heating in a baroclinic atmosphere. J. Atmos. Sci., 52, 307-319, doi:10.1175/1520-0469(1995)052<0307:TDRTTH >2.0.CO;2.

Jones, C., D. E. Waliser, K. M. Lau, and W. Stern, 2004: The Madden-Julian oscillation and its impact on Northern Hemisphere weather predictability. Mon. Wea. Rev., 132, 1462-1471, doi:10.1175/1520-0493(2004)132<1462: TMOAII $>2.0 . \mathrm{CO} ; 2$.

—, J. Gottschalck, L. M. V. Carvalho, and W. Higgins, 2011: Influence of the Madden-Julian oscillation on forecasts of extreme precipitation in the contiguous United States. Mon. Wea. Rev., 139, 332-350, doi:10.1175/2010MWR3512.1.

Kalnay, E., and Coauthors, 1996: The NCEP/NCAR 40-Year Reanalysis Project. Bull. Amer. Meteor. Soc., 77, 437-471, doi:10.1175/1520-0477(1996)077<0437:TNYRP>2.0.CO;2.

Kiladis, G. N., J. Dias, K. H. Straub, M. C. Wheeler, S. N. Tulich, K. Kikuchi, K. M. Weickmann, and M. J. Ventrice, 2014: A comparison of OLR and circulation-based indices for tracking the MJO. Mon. Wea. Rev., 142, 1697-1715, doi:10.1175/ MWR-D-13-00301.1.

Kobayashi, S., and Coauthors, 2015: The JRA-55 reanalysis: General specifications and basic characteristics. J. Meteor. Soc. Japan, 93, 5-48, doi:10.2151/jmsj.2015-001.

Liebmann, B., and C. A. Smith, 1996: Description of a complete (interpolated) outgoing longwave radiation dataset. Bull. Amer. Meteor. Soc., 77, 1275-1277.

Lin, H., and G. Brunet, 2009: The influence of the Madden-Julian oscillation on Canadian wintertime surface air temperature. Mon. Wea. Rev., 137, 2250-2262, doi:10.1175/2009MWR2831.1.

—,- , and J. Derome, 2009: An observed connection between the North Atlantic Oscillation and the Madden-Julian oscillation. J. Climate, 22, 364-380, doi:10.1175/2008JCLI2515.1.

, - - and R. Mo, 2010: Impact of the Madden-Julian oscillation on wintertime precipitation in Canada. Mon. Wea. Rev., 138, 3822-3839, doi:10.1175/2010MWR3363.1. 
Madden, R. A., and P. R. Julian, 1994: Observations of the 4050-day tropical oscillation-A review. Mon. Wea. Rev., 122, 814-837, doi:10.1175/1520-0493(1994)122<0814: OOTDTO $>2.0 . \mathrm{CO} ; 2$

Matthews, A. J., B. J. Hoskins, and M. Masutani, 2004: The global response to tropical heating in the Madden-Julian oscillation during the northern winter. Quart. J. Roy. Meteor. Soc., 130, 1991-2011, doi:10.1256/qj.02.123.

Mori, M., and M. Watanabe, 2008: The growth and triggering mechanisms of the PNA: A MJO-PNA coherence. J. Meteor. Soc. Japan, 86, 213-236, doi:10.2151/jmsj.86.213.

Paegle, J. N., L. A. Byerle, and K. C. Mo, 2000: Intraseasonal modulation of South American summer precipitation. Mon. Wea. Rev., 128, 837-850, doi:10.1175/1520-0493(2000)128<0837: IMOSAS $>2.0 . \mathrm{CO} ; 2$.

Pohl, B., and P. Camberlin, 2006: Influence of the Madden-Julian Oscillation on East African rainfall. I: Intraseasonal variability and regional dependency. Quart. J. Roy. Meteor. Soc., 132, 2521-2539, doi:10.1256/qj.05.104.

Reichler, T., and J. O. Roads, 2005: Long-range predictability in the tropics. Part II: 30-60-day variability. J. Climate, 18, 634650, doi:10.1175/JCLI-3295.1.

Sardeshmukh, P. D., and B. J. Hoskins, 1988: The generation of global rotational flow by steady idealized tropical divergence. J. Atmos. Sci., 45, 1228-1251, doi:10.1175/1520-0469(1988)045<1228: TGOGRF $>2.0 . \mathrm{CO} ; 2$.

Sato, H., R. Nagasawa, K. Miyaoka, M. Hirai, Y. Takaya, S. Matsueda, A. Shimpo, and H. Sugimoto, 2014: Performance of JMA's new one-month ensemble prediction system. CAS/ JSC WGNE Research Activities in Atmospheric and Oceanic Modelling, Vol. 44, No. 6, 13-14. [Available online at http://
www.wcrp-climate.org/WGNE/BlueBook/2014/individualarticles/06_Sato_Hitoshi_WGNE_bluebook2013_K1verif. pdf.]

Schreck, C. J., J. M. Cordeira, and D. Margolin, 2013: Which MJO events affect North American temperatures? Mon. Wea. Rev., 141, 3840-3850, doi:10.1175/MWR-D-13-00118.1.

Seo, K.-H., and S.-W. Son, 2012: The global atmospheric circulation response to tropical diabatic heating associated with the Madden-Julian oscillation during northern winter. J. Atmos. Sci., 69, 79-96, doi:10.1175/ 2011JAS3686.1.

Vitart, F., and F. Molteni, 2010: Simulation of the Madden-Julian Oscillation and its teleconnections in the ECMWF forecast system. Quart. J. Roy. Meteor. Soc., 136, 842-855, doi:10.1002/ qj.623.

Waliser, D. E., K. M. Lau, W. Stern, and C. Jones, 2003: Potential predictability of the Madden-Julian oscillation. Bull. Amer. Meteor. Soc., 84, 33-50, doi:10.1175/BAMS-84-1-33.

Wheeler, M. C., and H. H. Hendon, 2004: An all-season real-time multivariate MJO index: Development of an index for monitoring and prediction. Mon. Wea. Rev., 132, 1917-1932, doi:10.1175/1520-0493(2004)132<1917:AARMMI>2.0.CO;2.

, S. Cleland, H. Meinke, and A. Donald, 2009: Impacts of the Madden-Julian oscillation on Australian rainfall and circulation. J. Climate, 22, 1482-1498, doi:10.1175/2008JCLI2595.1.

Zhang, C., 2005: Madden-Julian Oscillation. Rev. Geophys., 43, RG2003, doi:10.1029/2004RG000158.

Zhou, S., M. L'Heureux, S. Weaver, and A. Kumar, 2012: A composite study of the MJO influence on the surface air temperature and precipitation over the continental United States. Climate Dyn., 38, 1459-1471, doi:10.1007/s00382-011-1001-9. 